\title{
Time and the Design of Web-Based Learning Environments
}

\author{
Ari M. Wahlstedt \\ University of Jyväskylä, Jyväskylä, Finland
}

\section{Ari.Wahlstedt@iyu.fi}

\begin{abstract}
For novice designers dealing with a mass of information, the initiation phase of design of a webbased learning environment can last much longer than for professional designers. A professional designer can with the help of experience surmount technological, cultural and social barriers that might prevent the design of a good learning environment. However, the time aspects of information, what is needed in design and information, what is used in learning, can result re-design and re-learning. From the designers' perspective, we observe what information they use. We focus especially on analyzing how they understand the time aspect of learning. From the users' perspective we discuss what time means to them in learning. The change in information happens in a certain period of time. We think that there should be more attention to this aspect in the design and propose hypothetical tools that might help filling the gap between design and use.
\end{abstract}

Keywords: design, designer, web-based learning environment, time, learning, information

\section{Introduction}

Design can be seen as a form of creation, which involves complexity and synthesis (Goel \& Pirolli, 1992; Schön, 1987). In a broad sense, anyone who designs is a designer. This means that unlike analysts or critics, designers put elements together and bring new creations into being. In so doing they deal with many variables and constraints, some initially known and some discovered through the design process (Eteläpelto, 1998). According to Burgoon, Buller, and Woodall (1996), it is typically human to affect and change one's environment. However humans are affected by their physical surroundings as well. Schön (1987) perceives all human constructive and creative activity as design; artists are clearly designers since they make things, songs, paintings and so on. Thus, design can be seen as a cognitive process characteristic of all humans, as noted in general and cognitive psychology (Goel \& Pirolli, 1992; Miller, Galanter \& Pribram, 1960). The products of this cognitive process are internal and external representations of how things could be put together. From another point of view (Leppälä, Kerttula, \& Tuikka, 2003), design is a goal-oriented process, which aims to produce a new technical artifact - a product to be manufactured by industrial methods and on an industrial scale. In this paper we consider that product as a web-based learning environment. We classify the designer of the web-based learning environment as follows: a designer is a person who is actively involved in the design process, plans

how the environment is going to be

Material published as part of this journal, either on-line or in print, is copyrighted by Informing Science. Permission to make digital or paper copy of part or all of these works for personal or classroom use is granted without fee provided that the copies are not made or distributed for profit or commercial advantage AND that copies 1) bear this notice in full and 2) give the full citation on the first page. It is permissible to abstract these works so long as credit is given. To copy in all other cases or to republish or to post on a server or to redistribute to lists requires specific permission from the publisher at Publisher@InformingScience.org used, affects and can change the environment via design.

The design of a web-based learning environment, e.g. for distance education purpose includes (Manninen \& Pesonen, 1997) consideration of different learning systems platforms, learning conceptions, didactical ap- 
proaches, special features of the target group (age, education etc.), special features of the web environment used (internet, intranet etc.), content and general focus of education. The design of a web-based learning environment in general starts first with the specification of purpose and definition of the features of the target group. If possible, it is important in design to take into account the planned users' backgrounds, aims, learning skills and conceivable problems in learning. When the aims are defined, it is time to examine the focus of education and find the relevant content to append.

In this paper we are interested in the time aspect of information, what is needed in the design and also the time aspect of what is used in learning. The time aspect of information is a part of that information which the designers use as a baseline in design. The time aspect of what is used in learning is a part of information that the learner uses when working with the learning environment. We separate that information into the cognitive content of the student and the learning content of the environment, thus what is represented as content in the learning environment. The underlying thought is if designers design products from a certain baseline, will the baseline affect the learning content and use. We consider in this paper mainly the time aspect of information in the designers' work. For a start, the terms information, learning and their time aspects are briefly described. Then the on-going research with designers and partial results are explained as a base for our hypothetical proposal of tools for designers' work. We end this paper with a discussion and future remarks by highlighting the main points.

\section{Information and Learning}

We start first with an examination of the term information from the area of information technology, especially in the area of information systems, because the term information has been the main denominator in that field and the term is frequently discussed technically and philosophically (Boland, 1987; Capurro, 1996; Capurro, \& Hjørland, 2003; Mingers, 1995). Discussion in the other areas of science should not be put aside right away, but the nature of web-based learning environments is technically connected to the design of information systems and we want to emphasize that connection in this paper. On the other hand, learning in this paper, is discussed from the educational point of view. As we see it, information is more of a formation outside/between objects and subject than plain formation inside the subject, and that learning is more of a formation inside/between subject and objects.

Boland (1987) claims that the essence of information is revealed in its name "in-formation". He explains that the information is inward-forming. Mingers (1995) found that even though information systems (IS) presumably could not exist without information and there is (in 1995) little agreement within the IS discipline over the nature of information itself, there are two compelling views (processed data and processed data plus meaning) expressed within the IS literature. Boland's term inward-forming seems to concern the latter. Capurro (1996; Capurro, \& Hjørland, 2003) has studied the concept of information and found that the denomination of the action of imparting knowledge as 'information' has its origins in the Latin and Greek roots of this word, namely in informare, in the ontological sense of moulding or forming a piece of matter and, metaphorically, human knowledge. Capurro also notes that the relation between ontology and epistemology played a significant role in ancient Greek philosophy and proposes a genealogy of information as an anthropological category. Despite the fact that semantics is challenging and meanings can be lost in action (Capurro, 1996), something can, from our next point of view, function as common ground. Boland says that information is the change in a person from an encounter with data, a change in the knowledge, beliefs, values or behaviour of that person. Shannon in his famous paper (1948) about information theory limits states: 
"Information and Uncertainty are technical terms that describe any process that selects one or more objects from a set of objects. We won't be dealing with the meaning or an implication of the information since nobody knows how to do that mathematically".

As well as with information, different theories and approaches describe learning from many perspectives. The three main theories, mostly know as behaviouristic, constructionist and cognitive approaches all contain the same starting point. Thus, there is human information and learning. The human is easy to recognize, but learning is not as easy to recognize. Illeris (2002) offers four different meanings for learning, which may more or less be included when the word is used without further specification in everyday language; the word learning refers to 1) the results of individual learning processes, thus what is learned, 2) the individual psychological processes, thus learning processes, 3 ) the interaction processes (when combined with learning processes) and 4) the teaching, which may be interpreted as the result of a tacit short circuit between what is taught and what is learned. Consequently we may see that we are dealing with concepts that are hard, maybe impossible to formalize. However, as we see things from different perspectives, we also try to understand them - and obviously from these varying perspectives. Formalizing concepts is one perspective to understand phenomena.

\section{Information in the Designers' Work as Baseline for Design}

A designer is a skilful person and co-operates with other designers and experts in order to achieve good results in design. However as an individual, his own level of expertise and knowledge about issues related to the design task define the overall effort of his work. Johannsen (1997) presented six knowledge modules for supporting the designers' work with the multi-human machine interfaces (Figure 1): goals, application, users, task, human-machine interface (HMI) issues and design procedures. Each of these modules presents information from different areas. For a novice designer understanding and applying the knowledge from them is time-consuming. According to our research, the same modules are present in the design work of web-based learning environments. Designers of web-based learning environments have information about design methods, HMI issues and other presented knowledge modules. However the studied designers $(\mathrm{N}=10)$ had different roles (e.g. job concerning mainly graphical design, coding, etc.) and their information about these knowledge modules issues varied. Those who considered themselves as designers had job titles like designer, developer, senior partner, chief technology officer, project manager and senior researcher. In this sense, designers are not using all the information presented in these knowledge modules. A limitation of our inquiry with designers was the time, because it is diffi-

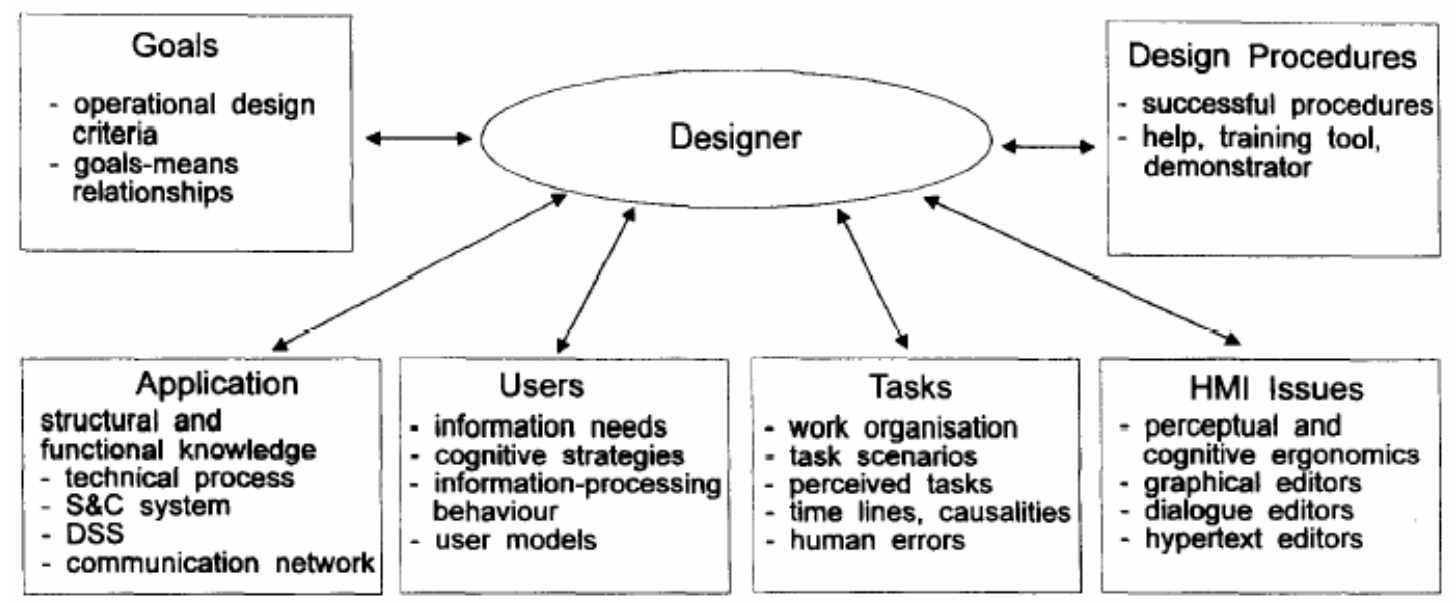

Figure 1: Knowledge modules for supporting the designer. From Johannsen, 1997. 
cult in a limited survey to have a picture of how much information and what information a designer is using in his task. Perhaps a better approach would be to ask tentative questions related to each of the knowledge modules. However, we can conclude briefly that the designers' design work requires information. Thus, the amount and quality of information affect the design work or in general the information that the designer receives from his environment and the information that he already has affects.

\section{Other Roles Interacting with Designers' Roles}

At this point we want to point out also other roles that interact with web-based learning environments, because they have an affect on the designers' work. We have defined these roles as student, teacher and content producer as follows. The content producer produces content for the environment according to e.g. the design plan; teachers and students are the most likely users of the planned environment. The teacher is a specialist of the context and works as a mediator between use and the content represented in the environment. The student is the presumed user of the environment. Thus, related to the learning environment, these roles have different tasks and aims. Our concern is the interaction between them. According to Häkkinen (1996), teacher-student interaction is physically and socially quite directly two-way. In this kind of interaction, the teacher can influence the learning situations from the basis of his situational interpretations. The contextual problem is that the interaction usually between the designers and students and also with the teachers is indirect. The involvement of the designers usually ends after software design is ready and designers' do not usually interact directly with students and thus, the intentions of use have to be built implicitly inside the environment. Also if we consider the life-cycle of a learning environment and the interaction between content producers and designers, there is the possibility that content producers operate indirectly with designers offering suitable content to customers of webbased learning environments vendors e.g. schools, companies etc. However, we observed in our research that some vendors designed and produced content of web-based learning environments or at least had the possibility to do so. We discuss our observations more in the discussion part, because there were mixed roles involved in companies where the design and the content production were done by the same person.

\section{Information and Students}

Also the users of web-based learning environment, limited here to students, seek information. They are inwardly or outwardly guided to use the environment to look for answers to their question or fulfil their purpose. Designers are able to plan the support for information that is first appended to the environment or to add guidance where the information should be found. Without deep understanding of all students' personal cognitive strategies or information processing behaviours, designers use user models for defining the suitable support for the learning content. This is obvious, because e.g. in distance education it is most likely that the designers of web-based learning environments do not have the opportunity or the time to become familiar with all the most likely users. Selected learning content is information presented with the help of different media. Thus, learning environments combine different media which are content consisting of static documents or other learning materials, hyperlinks between them or even the material created by the user. This content can be seen also as a function of a boundary object (Star \& Griesemer, 1989), which offers a stable point for surrounding action. A boundary object contains text, hypertext, hypermedia, links, recorded discussion and other channels of interaction. Overall this information, when presented, is interpreted by the user and it is first objective and becomes then a part of users' learning. Thus the information in web-based learning environments is a mediator between the environment and the user. And, if there is no other connection between student and teacher, this mediator works as the base of interaction between them. This is one reason why we 
think that the place where the learning content is available (e.g. via learning platform) is important and how it is available and also how the place is designed.

\section{Time Aspect of Information and Learning}

It is important to be realistic about the amount of time it takes to learn complex subjects (Bransford, Brown, \& Cocking, 2000). Learning is time-consuming or we use time for learning and the amount of time it takes to learn material is roughly proportional to the amount of material being learned (Singley \& Anderson, 1989). For example, we measure the time that we use for reading, thinking and perhaps even the time that we use for shaping and arranging our conceptions. And the more odd and complex the handled things are, or the less we have experiences or perspectives of them, the more time is needed for learning. When the metacognitive skills (Hakkarainen, Lonka, \& Lipponen, 1997) are more developed, the estimation of our own time needed for learning becomes easier. However it is easier to reserve more than less time for studying, because then there is more time to have an overview. Isomäki \& Häkkinen (2001) claim that when speaking of temporal learning the focus is on the reflection of time. They point out that in order to learn and collaborate successfully; symmetry between the different aspects of temporality is needed. Furthermore, in order to design information systems for learning, the differences between particular groups and their time conceptions should be recognised.

Epstein (1989) named six areas, which can affect student motivation: grouping, task, authority, time, recognition and evaluation. Sometimes it is clear that students learn better if they use more time for studying. Students learn at different speeds and individual learning requires that all students have enough or suitable amount of time for their studying, not too much to be efficient or not too little to be of good quality. The most intellectual and motivated students get frustrated if they are required to slow down or do routine work assignments or multiple amounts compared to others. According to Pintrich and Schunk (1995) students' motivations are best supported through personalized teaching. Students who are motivated can enjoy their studies and learning. And every student should have enough meaningful and challenging study assignments and maybe even from their own perspective.

The world is full of information that either explicitly or implicitly contains some expressions about time. For example, in discussion forums the student's comment is marked with the creation time, logging time etc. In learning assignments the student, working in his learning environment, studies the subject of the assignment. The learning environment contains different kinds of information about the subject. The learner gathers and analyzes the information, which is reasonable for him and according to the assignment learns about the subject. With the time aspect of information he can adjust the relevant information to fit the purpose of the learning assignment. For example, a student knows that some books concerning information systems in education are written in the 1980's and others in the 1990's and his assignment is to create scenarios of the development of IS education. Thus, this student could make the conclusion that the books written in the 1980's have less information about the situation in the field in the 1990's and the later, written in the 1990's, book might confirm the earlier book's scenarios. The student is using the time aspect of information in his studies.

Next we concentrate on the designers' work with information through our research work, although the roles of content producers, teachers and students are as important. Our aim is to observe first one role at a time and later in research expand to explore those other roles, and thus interactions among them. Then we have some sense of how differently roles exclude or are distinct from each other and are there interactions in between them. 


\section{Designers' Point of Views of Time and Learning}

From the designers' perspective, we observe what information they use and how it affects their work. We focus especially on analyzing how they understand the time aspect of learning. In our on-going research the designers were chosen among the participators in companies (150, in 2004) and projects (20, in 2004), which were concerned with web-based learning environment development. However, the target population in this paper is taken from our survey currently underway. The data used in this paper is a short analysis of data gathered between June and September 2004 and focusing only on designers (10 designers out of a total of 21 respondents). In this paper we do not attempt to make any generalizations, but instead our aim is to give a view of how designers might understand time and learning.

Designers were requested to participate and give answers to a web-survey. A survey is a suitable data collection method when a target group is large and there are few topics of questions (Järvinen \& Järvinen, 2001). It is a better method than an interview, in the sense that it can be better designed in advance and respondents can choose the moment when they answer. However, the researcher cannot inspect right away if the respondents have understood the questions, which require well-designed questions. In our web-survey, the average designer was a 32,7 -year old man working in a company's development team. Designers gave the first answer regarding questions about learning and time with the help of co-ordinates, thus they selected the most suitable place in the co-ordinate according to their conception. We refer to that process in this paper as a selection. Because of co-ordinates the selection was made with two dimensions at the same time and there were two co-ordinates where one dimension was about the time aspect of learning. After selection, designers were given an opportunity to explain and justify their selection with an open answer. The selection related to the time aspect of learning included two alternatives and their opposites; need or no need of time for learning and learning can be or cannot be scheduled. We defined scheduling of learning in our research as pre-planned and controlled learning process in a certain time period, thus demanding time. Six designers placed their selections pointing out that learning was something that demanded time and could be scheduled. Two of the designers had no opinion and only one placed the selection pointing out the opposite. However none of the designers place the selections to point out strongly the opposite, thus that learning is something that cannot be scheduled or did not need time. Thus learning seemed to be experienced as more timedependent. Even though we are not making a generalization, we thought this understandable, because everyday life seems to be time-dependent.

\section{Supporting Tools for Design}

Our results suggest that designers see learning as more time-dependent than independent of time. Also the students consider the time aspects of information in their studies, in learning. The information, which is offered through learning environments, such as representations like chats, slides, documents, links etc., is time-dependent. If we consider for example information that the learner gains from the learning environment about e.g. theories of physics, getting to know about time when it was formulized helps the student to have a perspective of different theories and consequences. Klausmeier (1985) notes learners, especially in school settings are often faced with tasks that do not have apparent meaning or logic and they may need time to explore underlying concepts and to generate connections to other information they possess. This information can be described as earlier information and also have time aspects. Thus, the learner needs to connect the new information to the earlier acquired information. The old information can be almost anything, because people have different educations and life experiences. This connection process takes time, and it is shown that when students are provided with opportunities to first grapple with specific information relevant to the topic, explanation about topic in the lecture is supported and enabled. But how can designers design support for this kind of process? How can they handle the 
necessary and used baseline time aspects and how do they classify support for learning context in such a way that it will support personalized learning? When is it the time to use and offer certain information to be used in the environment? Related to the last question, selecting the "right time", is what we want to next consider. What we think and suggest is a proposal of four hypothetical supporting tools for the design of web-based learning environments. We draw these tools from our experience of designers' work and from earlier research. Next we explain these hypothetical tools and give some examples of possible, comparable and available products.

The first tool concerns the issue of choosing a suitable learning platform for the learners. If the information about the users can be made adequately with the help of user models, then this first tool may be neglected. Starting from the requirements analysis, designers need information about the possible users. The methods and tools designers use to gain this information varies. For example earlier research (Kankaanranta, 2002; Niguidula, 1997; Pollari, 2000) has shown the possibilities of using portfolios in education. Referring to that approach we describe this first tool as the portfolio and systems analysis manager. The portfolio and system analysis manager application could be integrated into e.g. a student registry or other information system and could increase quality in the design by providing more detailed information and possibilities to search for information. Because designers have the possibility to choose learning platforms among open source products and rapid software development offers new technologies to be integrated with environments (e.g. instant messaging), we think that this tool could work so that the designer could have an overview of the student work in an earlier phase of student educational development (student profiles) and opportunities pick from a commercial or non-commercial vendors service a suitable platform (suitable system) and modules taking into consideration the curriculum. For example, a tool for presenting the time-lines of learners' earlier experience and education with background information about completed courses, thesis etc. This portfolio information about background and education might help designers to design environments in a way that users' learning receives more support. Also we think that designers' work load could be decreased, because this kind of tool akin could be adjusted to show only the information that designers need in their current design phase. However students should update prove their portfolios, which would be used. That would demand updating work by students or by another person. Furthermore security issues in linking personal data should be acknowledged and solved.

Examples and use of these kinds of managers were not found among designers and companies. For example, different registries and services used e.g. in companies and universities offer data, but the integration of systems and supportive interfaces in a form of a tool was missing. In our campus "Korppi"-information system it is possible e.g. for students to sign up for courses and staff to reserve spaces. This system serves also as an information repository about the available and on-going courses as well as containing information about students' studies and the university curriculum. The interface is accessed through the Internet, so students and staffs needs a username, password and computer connected to the Internet with a suitable web browser.

The second tool concerns the dynamic content and choosing relevant structures for information representation in the environment. For example, database and different mark-up languages (e.g. SQL, HTML and XML) provide the possibility to create learning content that can be linked, separated, and published in different forms. What is not changed is the chosen relevant information. How then can the designers support the content producers to add relevant information? What representation forms are supported? We suggest a tool that assists designers in designing preferred structures to be used. Designers have knowledge about the different possibilities of what technologies can be included and created, but do not quite know what is needed in the on-going course. With the help of teachers and content producers, designers could use a collaborative knowledge management tool, which would give an overview of the knowledge involved in a certain course and information about how the knowledge is planned to be presented. Commercial 
products for knowledge management are available but increasing information between participants needs more collaboration and open systems.

The third tool would be integrated into the previous in a way that it would give the possibility to view the different perspectives of the information presented in the design phase and the information used in the environment. This tool would be a kind of visualization tool that would give an overview of the information in the environment and the use of that information by participants of the learning environment. Visualizations can enhance awareness of the workplace (Leinonen, Sievänen, Järvelä, \& Häkkinen, 2003) and this kind of visualization of information -manager would aid designers in adjusting the environment during the use of an environment according to the actions and behaviours of participants (e.g. like GAW by Kreijns, Kirschner \& Jochems, 2002).

The final supporting tool that we suggest is a tool that integrates them all, a time manager. A time manager would show the timelines, creation dates, activation times etc. All the available timedata of the information related to the environment would be available. That time data could be viewed e.g. with the help of visualization of the information manager. With the help of the time manager designers could access the knowledge among participants in a certain time frame or view the group of students' actions in a given time frame, and design possible supportive and usable structures for their on-going and further actions. With the time manager, designers could follow different timelines of information. They could justify and refresh the structures of the environment in a way that the user would not need to struggle with his environment or leave the environment, because his information cannot be included in the environment or cannot have the necessary information. For example, in situation when a student has collected a database, but the format of that database is not supported by the environment and cannot be used through the environment. Some knowledge management software has chronological displays with the possibility to arrange student actions and information in the form of a timeline. According to our research, how those chronological displays help support students in their learning has not yet been studied.

\section{Right Time to Design}

As it is possible to propose tools for design, it is possible to reject and use different tools in design. Our proposed sets of tools are hypothetical; some can be integrated and implemented already, some perhaps in the future. However what we emphasize as important is the selection of "the right tools for the right task". When making this selection designers can think what the current situation is of learning in society. The designer who selected the only opposite alternative (learning cannot be scheduled) gave the following explanation of his choice of selection:

"For me scheduling and reserving time for learning sounds very "school-like". In my mind, the whole life is a part of the learning process, not just time, which is reserved separately. Learning can be scheduled in that sense that the learner consciously builds for himself a clear learning path, which is used for understanding certain things. That path is not filled with content, but it is full of situations, sociality, experiments, critical evaluations, exploration of deep knowledge and testing one's own thoughts. That is the reason why it cannot be measured in days or in hours, but it can be measured in milestones related to earlier corresponding experienced learning processes. I believe that the scheduling of learning in the way that e.g. "I learn now" and "Now I don't learn" can be destructive to individual development."

We found these observations interesting because the designer was the youngest designer (22) of the observation group and if we refer to the curriculum in our country's school systems, we can find that the curriculum tends to schedule the courses available mainly in two seasons, spring and autumn. Moreover, these courses are divided into periods of weeks, according to their credits and content. When taking into account web-courses, the starting point is the same. The course starts 
one day and ends another day, rarely are they over two months long. This is understandable, because the curriculum of education is tied to society's demands and possibilities. Time is one essential component in society; it gives possibilities for perspectives like "before" and "after".

The designer's work is influenced by his background, education, motivation, emotions and environment etc., mostly things that are before and now. When designers design web-based learning environments for users they cannot design precisely when users actually use the environment, unless that is described in the requirements or announced and controlled by the users. However designers need to think and plan what information is supported or what are the structures for supporting the presentation of information (e.g. Advanced Distributed Learning Initiative, 2004) at the time when the user is using the system: What time is it - for the user. We suggested four tools to answer this question. First the portfolio analysis manager, which help the designer to understand in what phase of life the students are. Then collaborative knowledge management for designers to understand what kind of knowledge is going to be involved and the visualization of the information manager to explore and understand different perspectives. Lastly, the time manager for designers to have the time aspect of the managed information: when to design and for what time.

\section{Final Remarks and Future Work}

In our research we have found that even though our object group classified themselves as designers quite clearly, the titles that they used and the work description they gave showed that their work is, more or less what we first classified as designers' work. For example, some designers designed the content for the environment, some worked as a teacher in the web-courses and some even worked as a manager in the company. This is quite usual, because people are not limited by their roles. Life is more than doing one precisely described job. When we classified in our context, in web-based learning environment development, what are the characteristics for designer, we found that some fit our classification well and others did not. However the most significant finding was that some people actually changed from being designers to be e.g. content producers. What we could not observe in our research was if they were switching also to be the users of the designed environment in actual courses. This should be researched more in the future, because as we shape our working environment daily e.g. office environment, open source software development enables users to construct their own web-based environments, where they can have or integrate the necessary content. Thus, we think that the possibility to design, to learn and to use information freely gives opportunities to designers to be the users and vice versa. However, the experience of users and also professional skills for managing information about users, task etc. counts in design work. In that design process, designers understand better what the user needs. Moles (1993) identified three barriers to family participation in the school activities of their children: limited skills and knowledge of teachers and parents, restricted opportunities for interaction and psychological and cultural barriers. We think that information and enhancing information technologies in the design of learning environments for distance education is a good support to overcoming barriers, as well as in interaction between teachers and parents, as in between designers, content producers, teachers and students.

\section{References}

Advanced Distributed Learning Initiative. (2004). Sharable Content Object Reference Model (SCORM) 2004 2nd Edition Addendum Version 1.1. Online paper from the ADL technical team. Retrieved January 20, 2005, from http://www.adlnet.org/index.cfm?fuseaction=SCORMDown

Boland Jr., R. J. (1987). The in-formation of information systems. In R. J. Boland Jr. \& R. A. Hirschheim (Eds.), Critical issues in information systems research (pp. 363-379). JohnWiley \& Sons. 
Bransford, J. D., Brown, A. L. \& Cocking, R. R. (2000). How people learn. Brain, mind, experience and school. National Academy Press.

Burgoon J. K., Buller, D. B. \& Woodall, W. G. (1996) Nonverbal communication. The unspoken dialogue. The McGraw-Hill Companies.

Capurro, R. (1996). On the genealogy of information. In K. Kornwachs \& K. Jacoby (Eds.), Information New questions to a multidisciplinary concept (pp. 259-271). Berlin: Akademie Verlag. Retrieved August 5, 2004, from http://www.capurro.de/cottinf.htm

Capurro, R. \& Hjørland, B. (2003). The concept of information. Annual Review of Information Science and Technology (ARIST), 37, 343-411. Retrieved August 5, 2004, from http://www.capurro.de/infoconcept.html

Epstein, J. (1989). Family structures and student motivation: A developmental perspective. In C. Ames \& R. Ames (Eds.), Research on motivation in education, goals and cognitions (Vol. 3, pp. 259-295). New York: Academic Press.

Eteläpelto, A. (1998). The development of expertise in information systems design. Jyväskylä: Jyväskylä University Printing House.

Goel, V. \& Pirolli, P. (1992). The structure of design problem spaces. Cognitive Science 16 (3), 395-429.

Hakkarainen, K., Lonka, K. \& Lipponen, L. (2001). Explorative learning (in Finnish). Porvoo: WS Bookwell.

Häkkinen, P. (1996). Design, take into use and effects of computer-based learning environments - Designer's, teacher's and student's interpretation. University of Joensuu.

Illeris, K. (2002). The three dimensions of learning. Roskilde: Roskilde University Press.

Isomäki, H.-K. \& Häkkinen, P. (2001). Information systems professionals' conception of learning: The intellectual basis for designing systems involving learning. In H.-K. Isomäki, J. Kari, M. Marttunen, A. Pirhonen \& J. Suomala (Eds.), Human centred technology and learning (pp. 157-189). Jyväskylä: Jyväskylä University Printing House.

Johannsen, G. (1997). Conceptual design of multi-human machine interfaces. Control Engineering Practice, 5 (3), 349-361.

Järvinen, P. \& Järvinen, A. (2001). On research methods. Tampere: Tampere University Press.

Kankaanranta. M. (2002). Developing digital portfolios for childhood education. (Doctoral dissertation, University of Jyväskylä, 2002). Jyväskylä: Institute for Educational Research.

Klausmeier, H. J. (1985). Educational psychology. New York: Harper \& Row.

Kreijns, K., Kirschner, P. \& Jochems, W. (2003). The sociability of computer-supported collaborative learning environments. Journal of Educational Technology and Society, 5 (1), 8-22.

Leinonen, P., Sievänen, A., Järvelä, S. \& Häkkinen, P. (2003, September). Enhancing virtual collaborative learning and working process with awareness tools. Paper presented at the Eight European Conference on Computer Supported Cooperative Work, Helsinki, Finland.

Leppälä, K., Kerttula, M. \& Tuikka, T. (2003). Virtual design of smart products. Cyberdesigner's notebook. Helsinki: Edita Publishing.

Manninen, J. \& Pesonen, S. (1997). New learning environments (in Finnish). Aikuiskasvatus, (4), 267-274.

Miller, G. A., Galanter, E. \& Pribram, K. H. (1960). Plans and the structure of behavior. New York: Holt, Rinehart \& Winston.

Mingers, J. C. (1995). Information and meaning: Foundations for an intersubjective account. Information Systems Journal, 5, 285-306. Blackwell Science. 
Moles, O. (1993). Collaboration between schools and disadvantaged parents: Obstacles and openings. In N. Chavkin (Ed.), Families and school in a pluralistic society (pp. 21-49). Albany, NY: State University of New York Press.

Niguidula, D. (1997). The digital portfolio: A richer picture of student performance. Retrieved November 3, 2004, from http://www.essentialschools.org/cs/resources/view/ces_res/225

Pintrich, P. \& Schunck, D. (1995). Motivation in education. Theory, research and applications. Englewood Cliffs, New Jersey: Prentice Hall.

Pollari, P. (2000). "This is my portfolio." Portfolios in upper secondary English studies. University of Jyväskylä. Institute for Educational Research.

Roberts, P. D. (2000). Dynamics of temporal learning rules. Physical Review E, 62, 4077-4082.

Schön, D.A. (1987). Educating the reflective practitioner. San Francisco: Jossey-Bass.

Shannon, C. E. (1948). A mathematical theory of communication. Bell System Technical Journal, 27, 379423 \& 623-656. Retrieved January 4, 2005, from http://cm.belllabs.com $/ \mathrm{cm} / \mathrm{ms} /$ what $/$ shannonday $/$ shannon1948.pdf

Singley, K. \& Anderson J. R. (1989). The transfer of cognitive skill. Cambridge, MA: Harvard University Press.

Star, S. L. \& Griesemer, J. R. (1989). Institutional ecology, 'translations' and boundary objects: Amateurs and professionals in Berkeley's Museum of Vertebrate Zoology, 1907-39. Social Studies of Science 19, 387-420.

Tuomi, I. (1999). Data is more than knowledge. Implications of the reversed knowledge hierarchy for knowledge management and organizational memory. Journal of Management Information Systems, 16 (3), 107-121.

\section{Biography}

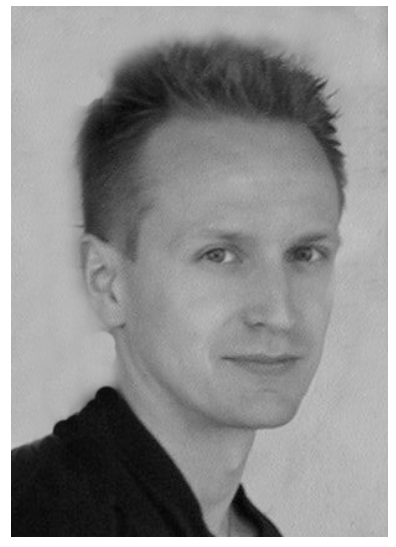

Ari M. Wahlstedt is currently pursuing his Doctoral Degree in University of Jyväskylä as a Ph. D. student at the Department of Computer Science and Information Systems. His multidisciplinary research topic about Designers' and Content Producers' Conceptions of Learning in Development Process of e-Learning Environments covers areas of Computer Science, Educational Science and Cognitive Psychology. 